\title{
Gestão democrática e escola justa: uma relação orgânica
}

\author{
Democratic management and fair school: \\ an organic relationship
}

\author{
Gestión democrática y escuela justa: \\ una relación orgánica
}

\author{
Dinair Leal da Hora* \\ ORCID: https://orcid.org/0000-0002-3278-3914 \\ Luziane Said Cometti Lélis** \\ ORCID: https://orcid.org/0000-0002-7870-9023
}

\begin{abstract}
Resumo: O presente artigo alude a relação estabelecida entre a gestão democrática e as concepções de escola justa, mostrando seus significados e suas possibilidades para a gestão escolar. O texto problematiza a administração no contexto da reforma de Estado que instituiu a gestão gerencial e definiu a luta entre duas lógicas - a democratização dos processos gestionários no interior da escola e o gerencialismo que atende aos interesses de mercado. Evidencia também que a discussão sobre justiça precisa estar e articulada com o tema das desigualdades que, por sua vez, adere às noções amplas de redistribuição, reconhecimento e representação. Aprofunda, ainda as concepções de escola justa, no modo como se (des)multiplicam no contexto educativo, tendo presente que a educação mobiliza diferentes registros, quer valorativos que apelam ao mérito, quer estatutários que obrigam ao respeito por determinados princípios (como o da igualdade de aces- so ao bem educativo), quer como expressivos, que favorecem o desenvolvimento e a autonomia. $O$ objetivo central do trabalho discutir os princípios e os fundamentos de gestão democrática e escola justa no contexto da justiça social, demonstrando sua profunda articulação para a promoção da justiça educacional. O estudo é resultado de revisão da literatura pela pesquisa bibliográfica.
\end{abstract}

Palavras-chave: Gestão democrática. Escola justa. Educação e justiça.

\begin{abstract}
This article alludes to the relationship established between democratic management and the concepts of fair school, showing its meanings and its possibilities for school management. The text problematizes administration in the context of the State reform that instituted managerial management and defined the strug- gle between two logics - the democratization of management processes within the school and managerialism that serves market interests. It also shows that the discussion on justice needs to be and articulated with the theme of inequalities, which, in turn, adheres to the broad notions of redistribution, recognition and represen- tation. It further deepens the conceptions of a just school, in the way they are (de) multiplied in the educational context, bearing in mind that education mobilizes different registers, whether values that appeal to merit, or statutory ones that require respect for certain principles (such as the equal access to the educational good), or as expressive, which favor development and autonomy. The main objective of the paper is to discuss the principles and foundations of democratic management and fair school in the context of social justice, demonstrating its profound articulation for the promotion of educational justice. The study is the result of a literature review by bibliographic research.
\end{abstract}

Keywords: Democratic management. Fair school. Education and justice.

\footnotetext{
* Professora Adjunta da UFPA, lotada no Campus Universitário de Abaetetuba, atuando no Curso de Pedagogia e professora permanente do Programa de Pós-Graduação em Currículo e Gestão da Escola Básica da Universidade Federal do Pará e do Programa de Pós-Graduação em Educação na Amazônia. E-mail: tucupi@uol.com.br.

** Possui graduação em Pedagogia. Especialização em Educação e Informática. Mestrando em Currículo e Gestão da Escola Básica da UFPA.Coordenadora Pedagógica da SEMEC/Belém. E-mail: luziane.bimgmail.com.
} 
Resumen: Este artículo alude a la relación establecida entre la gestión democrática y los conceptos de escuela justa, mostrando sus significados y posibilidades para la gestión escolar. El texto problematiza la admi- nistración en el contexto de la reforma del Estado que instituyó la gestión de gestión y definió la lucha entre dos lógicas: la democratización de los procesos de gestión dentro de la escuela y la gestión que sirve a los intereses del mercado. También muestra que la discusión sobre la justicia debe articularse con el tema de las desigualdades, que a su vez se adhiere a las nociones generales de redistribución, reconocimiento y repre- sentación. Profundiza aún más las concepciones de una escuela justa, en la forma en que se (des) multiplican en el contexto educativo, teniendo en cuenta que la educación moviliza diferentes registros, ya sean valores que merecen el mérito o estatutos que requieren el respeto de ciertos principios (como el igual acceso al bien educativo), o como expresivo, que favorecen el desarrollo y la autonomía. El objetivo principal del documento es discutir los principios y fundamentos de la gestión democrática y la escuela justa en el contexto de la jus- ticia social, demostrando su profunda articulación para la promoción de la justicia educativa. El estudio es el resultado de una revisión de la literatura por investigación bibliográfica.

Palabras clave: Gestión democrática. Escuela justa. Educación y justicia.

A narrativa da justiça foi, e ainda é hoje, objeto de interpretações várias e conflituantes. Assim, ela foi interpretada como: tolerância, lei natural ou direitos naturais; como utilidade ou como respeito pela pessoa; como equidade, imparcialidade e liberdade igual; como igualdade jurídica ou como igual respeito e consideração; como capacidade ou possibilidade de realização daquilo que cada um valoriza, entre muitas outras definições. (ESTEVÃO, 2004).

\section{INTRODUÇÃO}

O tema da justiça está intimamente articulado com o das desigualdades e este, por sua vez, com as noções amplas de redistribuição, reconhecimento e representação. Isto significa que a noção de justiça é complexa, englobando várias dimensões que, na prática, podem colidir entre si ou manter se em estado de tensão.

No campo da educação, e não obstante a pesada tradição da sua ocultação, a justiça tem vindo a ser resgatada, emergindo como um conceito também multidimensional e como um outro nome da educação, pela capacidade de reconhecer poder os atores educa- tivos na qualidade de pessoas com direitos culturais, políticos e sociais.

O presente artigo, resultado de revisão da literatura pela pesquisa bibliográfica, cujo objetivo central do discutir os princípios e os fundamentos de gestão democrática e escola justa no contexto da justiça social, demonstrando sua profunda articulação para a promoção da justiça educacional, tratando da relação que se estabelece entre a gestão democrá- tica e as concepções de escola justa, mostrando seus significados e suas possibilidades para a gestão escolar.

O texto problematiza a administração no contexto da reforma de Estado que instituiu a gestão gerencial e definiu a luta entre duas lógicas - a democratização dos processos gestionários no interior da escola e o gerencialismo que atende aos interesses de mercado, além disso, evidencia também que a discussão sobre justiça precisa estar e articulada com o tema das desigualdades que, por sua vez, adere às noções amplas de redistribuição, reconhecimento e representação.

O trabalho busca aprofundar, ainda, as concepções de escola justa, no modo como se (des) multiplicam no contexto educativo, tendo presente que a educação mobiliza diferentes registros, quer valorativos que apelam ao mérito, quer estatutários que obrigam ao respeito por determinados princípios (como o da igualdade de acesso ao bem 
educativo), quer como expressivos, que favorecem o desenvolvimento e a autonomia.

\section{CONCEPÇÕES DE JUSTIÇA E SUA RELAÇÃO COM EDUCAÇÃO E A ESCOLA}

A abordagem do conceito de justiça, que a retira do sentido jurídico-formal, incluindo-a no sentido eminentemente político, ético, filosófico, cultural e sociológico, permite compreender sua relação orgânica com os conceitos de igualdade, equidade, liberdade, mérito, poder, autoridade, entre outros, que condicionam, de modo particular, a maneira como pensamos a educação e a forma como as escolas se organizam para cumprirem suas finalidades.

As concepções que se tem acerca de justiça são tão diversas quanto os princípios utilizados para defini-la. Estêvão (2004) debruça se nas diferentes abordagens de justiça, procurando, de uma maneira didática, organizar de acordo com três perspectivas: a universalista, a pluralista, e a radical.

$\mathrm{Na}$ perspectiva universalista podemos localizar a Justiça $(\mathrm{Re})$ Distributiva, sistematizada por John Rawls (2008) e considera que uma sociedade bem ordenada é aquela na qual existem mecanismos compensatórios e regulatórios legais, capazes de diminuir as desigualdades econômicas e igualar as oportunidades de emprego.

Na perspectiva pluralista encontramos a Justiça Variável ou Plural, cujo principal representante é Michael Walzer (2003) para quem a justiça será diferente a partir do contexto social tratado; um bem jurídico com um estimado valor naquela sociedade, poderá ser elevado ao status de "direitos fundamentais" e ter uma estabilidade constitucional rígida.

Já a perspectiva radical crítica às perspectivas universalista e pluralista, trazendo para o centro a concepção de justiça social como repartição de bens materiais e distribuição de posições sociais; quando se estende aos bens sociais imateriais - poder de decisão, oportunidade e respeito próprio -, eles passam a ser representados como "coisas estáti- cas", em vez de processos que regem as relações sociais. Iris Young (1990), Nancy Fraser (2007) e François Dubet (2004) são os principais representantes da perspectiva radical de justiça.

John Rawls (2008) é o principal representante da corrente universalista. De acordo com essa perspectiva quando se procura um significado de justiça, "a tendência é que se procure um princípio que define o que é justo ou in justo e que seja aceite por todos os envolvidos num discurso prático, sob condições perfeitas de simetria e igualdade nas oportunidades de participação". (ESTÊVÃO, 2004, p. 17).

A teoria da justiça de Rawls costuma ser rotulada como liberal e igualitária. É liberal porque pretende garantir a tolerância e a liberdade individual. É também igualitária porque valoriza a igualdade econômica e social. Essas duas facetas da teoria estão presentes nos seus dois famosos princípios de justiça. 
Primeiro: cada pessoa deve ter um direito igual ao sistema mais extenso de iguais liberdades fundamentais que seja compatível com um sistema similar de liberdades para outras pessoas. Segundo: As desigualdades sociais e econômicas devem estar dispostas de tal modo que tanto (a) se possa razoavelmente esperar que se estabeleçam em benefício de todos como (b) estejam vinculadas a cargos eposições acessíveis a todos (2008, p. 73).

Sobre o primeiro princípio o da liberdade igual, Rawls afirma que todas as pessoas devem possuir um sistema de liberdades básicas e de direitos iguais para todos, na qual este programa, para sua plena e satisfatória existência, deva ser compatível com os programas de direitos e liberdades de outros indivíduos. Assim, Rawls busca dizer que existem certos direitos e liberdades que devem ser privilegiados em detrimento de outros direitos e liberdades existentes em sociedade. As liberdades básicas supracitadas devem ser de outros direitos e liberdades existentes em sociedade. As liberdades básicas supracitadas devem ser compreendidas como:

[...] a liberdade política (direito ao voto e a exercer cargo público), a liberdade de expressão e de reunião, a liberdade de consciência e de pensamento, a liberdade individual, que compreende a proteção contra a opressão psicológica, a agressão e a mutilação (integridade pessoa), o direito à propriedade pessoal e a proteção contra prisão e detenção arbitrárias, segundo o conceito de Estado de Direito. O primeiro princípio estabelece que essas liberdades devem ser iguais. (RAWLS, 2008, p.74).

Quanto ao princípio da oportunidade justa e o princípio da diferença Rawls teoriza que quando as teoriza que quando as pessoas estiverem condições iguais deverão ter acesso às mesmas chances. Desse modo, as desigualdades econômicas e sociais devem estar ligadas a postos e posições acessíveis a todos em condições de igualdade de oportunidades. Contudo, neste princípio a desigualdade pode ser permitida se ela beneficiar os menos favorecidos. Logo o Estado deve ajudar mais os que necessitam, ou seja, o Estado deve dar mais oportunidades para os menos privilegiados, para que estes possam ter acessos aos bens primários. Sendo assim, seguindo esses princípios para reestruturar a sociedade, conseguiremos torná-la justa. Rawls (2008) atribui a esses princípios uma escala de prioridade: o primeiro tem prioridade sobre o segundo; e a primeira parte do segundo (a) tem prioridade sobre a segunda parte (b) o que permitiria a coexistência de diferentes modos de vida.

Sendo assim, percebe-se que Rawls defende o primeiro princípio da justiça como garantidor do direito à liberdade, dando proteção à autonomia como o valor base para a realização do indivíduo. Cabe a uma sociedade bem ordenada garantir as condições básicas para uma vida autônoma. Para isso, se deve garantir aos sujeitos uma lista de bens primários, como oportunidades de acesso a posições de autoridade, rendas, riquezas e cargos valorizados pela sociedade. No entanto, se tais bens não forem ofertados equitativamente distribuídos, a liberdade não teria, segundo Silva (2004), o mesmo valor paratodos, pois a autonomia exige o acesso equitativo a um mínimo de benefícios sociais.

A garantia das condições básicas para uma vida autônoma depende de uma educação que faculte, ao longo da vida, qualificação profissional, sem a qual não se pode 
garantir a igualdade de oportunidades de acesso a empregos e cargos, e que possibilite desenvolvimento das capacidades morais, indispensáveis para a vida cívica. $\mathrm{O}$ direito à educação torna-se então fundamental para uma sociedade bem ordenada. Os recursos públicos destinados à educação devem ser negociados de modo que não se desrespeite os princípios da justiça. A educação compulsória precisa ser publicamente controlada, nas diferentes instâncias deliberativas, para se garantir o desenvolvimento das capacidades morais, bases de autonomia racional e razoável das pessoas. (SILVA, 2004, p.6).

Os dois princípios e a prioridade dos mencionados direitos básicos seriam aceitos em uma posição original de igualdade, em que ninguém conheceria sua situação familiar, financeira e mesmo pessoal, pois ignoraria também quais seriam suas habilidades e talentos. Esse desinteresse decorrente da falta de conhecimento da própria situação determinaria que alguém não pudesse discordar desses princípios, sendo a posição original o estado ideal para essa decisão, pois o véu de ignorância garantiria que homens racionais decidissem em situação equitativa, em que todos estariam em situação semelhante e ninguém poderia fixar regras para beneficiar sua própria situação. Se as liberdades individuais estão garantidas, convivendo harmonicamente as diferentes concepções de vida, arranjos institu- cionais devem ser utilizados para viabilizar o ideal igualitário que também se faz presente. Do que foi exposto, vê-se que Rawls pretende tratar as pessoas como iguais sem remover todas as desigualdades, mas apenas aquelas que trazem prejuízo a alguém. Se alguém, utilizando, por exemplo, seu talento, beneficia de alguma forma a todos, a desigualdade resultante é permitida.

Com visões antagônicas às posições universalistas, a perspectiva pluralista propõe a justiça de forma mais contextualizada, isto é, enquanto ligada a uma comunidade política concreta - com tradição comum e significados sociais comuns, podendo ser especifica de cada esfera social - como na educação, no trabalho, na saúde etc. Sendo assim:

[...] não há como se estabelecer uma teoria de justiça fundamentada em princípios imparciais e universais, muito menos na existência de indivíduos abstratos, sem raízes, livres de qualquer influência histórica ou cultural, conforme defendido pela teoria da justiça de John Rawls, para quem os indivíduos devem escolher os princípios de justiça protegidos pelo "véu da ignorância", ou seja, privados de suas próprias personalidades, contingências históricas e concepções particulares acerca da vida digna. (TAVARES, 2009, p.7218).

Segundo Ribeiro (2014), para Rawls (2008), o princípio da igualdade de oportunidades não pode ser anulado, uma vez que, nas sociedades democráticas, é preciso garantir a ideia de liberdade básica do indivíduo e não somente a de igualdade. Essa garantia pressupõe a preservação da mobilidade social que se regulamenta pela igualdade de oportunida- des, a qual, por sua vez, contempla o mérito. Entretanto, do ponto de vista da organização da vida social e política, o referido autor apresenta 0 conceito de igualdade equitativa de oportunidades: o foco não é sobre o indivíduo que merece mais ou menos devido a seus talentos, mas, sim, sobre os arranjos institucionais menos ou mais capazes de gerar igualdade de oportunidades e garantir, simultaneamente, igualdade e liberdade.

O autor Michael Walzer (2003), tido como o autor mais representativo desta corrente 
(ESTÊVÃO, 2004), considera que toda a sociedade é uma comunidade distributiva, na qual a dominação se exerce frente à forma como se utilizam dos bens sociais. Neste modo de pensar, ele presume que uma determinada sociedade só será justa se a sua vida for vivida de uma maneira fiel às compreensões partilhadas dos seus membros e que, portanto, qualquer demonstração da justiça distributiva será sempre uma explicação local.

A teoria de justiça de Walzer começa com a afirmação de que os homens vivem em uma comunidade distributiva, portanto, a ideia de justiça social tem a ver não só com a produção e o consumo, mas também com o processo de distribuição dos bens sociais. Para Walzer, essa distribuição não é simples. Isso porque não há apenas um bem social, assim como não há apenas um critério de distribuição ou um único agente distribuidor. Muito pelo contrário, a vida em comunidade revela um vasto rol de bens sociais, com diferentes agen- tes distribuidores e diferentes critérios de distribuição. Assim, para Walzer, qualquer sistema distributivo que não levar em consideração essa complexidade de fatores não conseguirá alcançar a realidade da pluralidade humana. Além disso, a escolha dos princípios que re- gulam esse sistema distributivo deve ser feita levando-se em consideração o particularismo de cada comunidade, suas características históricas e culturais. (TAVARES, 2009, p.7219) Walzer (2003) propõe uma sociedade organizada em esferas que possuem caracte- rísticas e necessidades próprias e têm os seus próprios critérios de distribuição. É a igual- dade complexa de Walzer. Por isso, é justo que a distribuição das diferentes oportunidades e dos diferentes bens sociais - segurança, bemestar, educação, dinheiro, trabalho, tempo livre, poder político, amizade, igualdade - seja feita de acordo com a necessidade, o mérito e o mercado de cada um desses mundos.

Então, podemos compreender uma teoria pluralista da justiça social como uma proposição, cuja meta é realizar a "igualdade complexa", que é [...] entendida como aquela que respeita a liberdade e que exige a distribuição dos bens sociais segundo uma diversidade de procedimentos e critérios (tais como a necessidade, o mérito e o mercado), ou seja, de acordo com o significado do bem social em causa. (ESTÊVÃO, 2004, p.20-21)

Nesta mesma corrente, nos sãos apresentados autores como Boltanski \& Thévenot (1991), que segundo Estêvão (2004) falam do mesmo pluralismo, tendo sua gênese nas estratégias de justificação concretizadas pelos atores sociais, no entanto, em situação de conflito ou controvérsias.

Para eles, a vida social consiste fundamentalmente em organizar compromissos entre vários mundos ou 'grandezas' que aí se constituem e que corporizam formas de bem comum. Por outras palavras, as relações sociais não podem resumir-se ao produto do hábito ou dos constrangimentos da cultura e da rotina. Elas implicam também acordos entre as pessoas, convenções, coordenações da ação coletiva, que exigem, para serem compreendidas, a referência a princípios que decorrem de vários referenciais ou, como eles dizem, de 'vários mundos'[...] $\mathrm{E}$, nesta sequenciam distinguem, como formas ideais- típicas, o mundo da inspiração, o mundo da opinião, o mundo doméstico, o mundo cívico, o mundo mercantil e o mundo industrial, cada qual com seu modo de generalização e de argumentação [...]. (ESTÊVÃO, 2004, pp. 23-24).

Postulado isto, podemos também perceber que os diferentes mundos apontam definições próprias para justiça. Estêvão (2004) exemplifica: o mundo doméstico tende a 
apelar para uma justiça familiar; já o mundo cívico é a ética da justiça, entendida como decorrente da argumentação racional, sem coações e onde a dimensão da solidariedade, da igualdade e do interesse público está presente, prevalece; no mundo industrial a justiça é articulada com a performance, com os procedimentos corretos visando à produtividade; no mundo mercantil a justiça é concebida como vinculada à ideia de justeza dos preços, do respeito pelos acordos e concorrências, do respeito pela propriedade privada; por último, a justiça do mundo da inspiração decorre da singularidade e criatividade, enquanto do mundo da opinião é apresentada com a justa reputação e opinião dos outros.

Uma análise final acerca deste conceito de justiça permite mobilizar muitas variáveis de argumentações subsidiadas por princípios diversos, uma vez que cada mundo apresenta um apontamento para critérios distintos de justiça, para valorizações distintas das ações. Como crítica ao paradigma distributivo da justiça, defendido pelas perspectivas uni- versalista e pluralista, Young (1990) vê dois problemas: o primeiro é que este paradigma tende a conceber a justiça social como a repartição de bens materiais e a distribuição de posições sociais; o segundo é que quando se estende aos bens sociais imateriais - poder de decisão, oportunidade e respeito próprio -, que passam a ser representados como "coisas estáticas", em vez de processos que regem as relações sociais.

Assim, a autora afirma que este modelo distributivo é o reforço da injustiça pela universalização das normas dos grupos dominantes a partir de políticas de distribuição que são cegas diferença, já que,

o paradigma distributivo além de reduzir a justiça a uma distribuição igual de direitos como se estes fossem simples bens materiais que se possuem e se distribuem, impõe uma norma igualitária que coage a diferença a tonar-se uniformidade; ou seja, esse paradigma tende a impor uma falsa identidade sob uma norma igualitária, o que faz com que as identidades individuais não compatíveis ou inconsistentes com esta norma sejam silenciadas, impedindo assim a contestação às concepções dominantes (nomeadamente de personalidade e de bem-estar). (ESTÊVÃO, 2009, p.115).

Young (1990) apresenta, então, um conceito de justiça que objetiva a eliminação da dominação e da opressão, no âmbito dos processos de tomada de decisão, da divisão do trabalho e cultura, segundo Estêvão (2004, p.30) "interessada numa política valorizadora da diferença”. Nas palavras da autora:

Opressão consiste em processos institucionais sistemáticos que impedem algumas pessoas de aprender e usar habilidades expansivas e satisfatórias em cenários socialmente reconhecidos, ou processos socialmente institucionalizados que inibem as habilidades das pessoas de agir e comunicar-se umas com as outras ou expres- sar seus sentimentos e perspectiva de vida social em contextos onde outros possam ouvir [...]. Dominação consiste em condições institucionais que inibem ou impedem as pessoas de participar na determinação ou condição de suas ações. As pessoas vivem dentro de estruturas de dominação se outras pessoas ou grupos podem determinar sem reciprocidade as condições de suas ações, quer diretamente, quer em virtude das consequências estruturais de suas ações. (YOUNG, 1990, p.38).

O problema da distribuição de recursos, que a autora denomina exploitation (exploração), é apenas uma das cinco diferentes faces da opressão. O fenômeno também 
se expressa pelo que a autora define como marginalization, powerlessness, cultural imperialism e violence.

Marginalization (marginalização) refere-se à maneira como certos grupos da sociedade são excluídos da participação na vida social e das oportunidades de trabalho estando, portanto, sujeitos a privações. Powerlessness (ausência de poder) remete à falta de autori- dade e respeitabilidade social que certos grupos da sociedade enfrentam, o que condiciona a própria capacidade de os indivíduos se desenvolverem. Um exemplo de powerlessness seria a maneira como, no Brasil, o não domínio da língua tida como oficial acaba por deslegitimar o próprio conteúdo da fala de indivíduos pertencentes a certos grupos da sociedade. (YOUNG, 1990)

(Outra face da opressão o cultural imperialism (imperialismo cultural), a saber, a universalização das experiências e da cultura de certos grupos como norma, decorrente do domínio que exercem sobre os meios de interpretação e comunicação na sociedade). O imperialismo cultural tem como consequência a estigmatização e a inferiorização de determinados grupos sociais, vistos como um desvio das normas, bem como a invisibilização de suas experiências.

Por último, Young inclui violence (violência) como forma de opressão, entendida não meramente como violência individual, mas sistemática, pois se baseia na permissibilidade ou aceitação social da violência contra indivíduos pertencentes a determinados grupos da sociedade. Um exemplo seria o constante temor que homossexuais e transgêneros sentem de vir potencialmente a ser vítimas de violência no espaço público por conta de sua orientação sexual. (YOUNG, 1990)

A partir dessa concepção mais ampla de opressão, é possível afirmar que redistribuição de bens e recursos não é condição suficiente para reverter as desigualdades sociais. Nas palavras da autora "A injustiça de exploração não pode ser eliminada pela redistribuição de bens, enquanto práticas institucionalizadas e as relações estruturais permanecem inalteradas, o processo de transferência irá recriar uma distribuição desigual dos benefícios". (YOUNG, 1990, p.53).

Young posiciona-se a favor da política da diferença como mecanismo capaz de romper com a opressão e dominação a que as minorias sociais estão submetidas. Tratase da proposição de uma sociedade civil constituída por múltiplos espaços públicos, nos quais os grupos articulam suas ideias e interesses, em que podem debater e influenciarse mutuamente, exercendo influência sobre as ações do Estado e sobre as instituições econômicas. Essa diversificação de atores na esfera pública permitiria, segundo a autora, a autodeterminação e o autodesenvolvimento dos grupos oprimidos.

Para tanto, a política da diferença deve converter-se em normas e políticas públicas, permitindo a coexistência de leis gerais com normas e direitos específicos a grupos oprimidos. Políticas de ação afirmativa, escolas indígenas bilíngues e direitos especiais para mulheres são algumas possibilidades de direitos específicos e cumprem, em especial, o papel de desmascarar a retórica universalista dos grupos dominantes que insistem em não enxergar seus próprios privilégios. 
Uma vez que ignorar as diferenças na política pública não significa que as pessoas as ignorem na vida e interação cotidianas, não importa como, a opressão continua mesmo quando a lei a e política declaram que todos são iguais. Sendo assim, eu penso que para muitos grupos e em muitas circunstâncias é mais válido afirmar e reconhecer na vida pública as diferenças entre grupos que já existem na vida social (YOUNG, 1990, p.169).

Para Young (1990), se não existissem as imposições das condições institucionais, cada indivíduo agiria conforme suas capacidades não havendo qualquer paradigma que colocasse as pessoas num mesmo patamar ou numa pretensa uniformidade e propõe, através do que denomina "democracia comunicativa", não só a inclusão da representação de grupos marginalizados no processo de deliberação, como também uma mudança dos arranjos institucionais a fim de que estes sejam mais sensíveis aos diferentes modos de expressão de perspectivas na sociedade.

A autora aposta que a melhor maneira de combater as distorções institucionais do processo deliberativo é assegurar que grupos subalternos possam formular, autonomamente, seus interesses em uma sociedade marcada pelas diversas "faces" de opressão. Assim, nesse primeiro momento, ela sugere que:

Tal representação de grupos implica mecanismos institucionais e apoio dos
recursos públicos (1) auto organização dos membros do grupo para assegurar o
empoderamento coletivo e uma compreensão reflexiva da experiência coletiva e
dos interesses no contexto da sociedade; (2) análise do grupo e geração de
propostas de políticas em contextos institucionalizados em que os responsáveis
pelas decisões são obrigados a mostrar que suas deliberações levaram em
consideração as perspectivas do grupo, e (3) pod er de veto sobre as políticas
específicas que afetam um grupo diretamente, como política de direitos
reprodutivos para as mulheres, ou a política de uso da terra para reservas
indígenas. (YOUNG, 1990, p.184).

Young (1990) argumenta que as políticas públicas devem enfraquecer a opressão dos grupos, afirmando, em vez de suprimir sua diferença. Sendo assim, ela defende que os grupos oprimidos, como as mulheres, os negros, os índios e, os homossexuais, por exemplo, devam ser representados, politicamente, aprovando e fazendo cumprir uma legislação, de modo a garantir que os direitos de tais grupos não sejam desrespeitados.

O tempo atual apresenta se como um tempo de grande vulnerabilidade social, em que noções como: precariedade e desemprego, emprego temporário, diferenciação, debilidade do movimento social, individualização das relações sociais, desigualdades, insegurança, incerteza, desregulação, fragilidade dos laços comunitários, feminização da pobreza, desqualificação e atomização social demarcam um campo semântico claro de inquietações profundas, apontando para as múltiplas formas como muitos são atingidos por um trabalho de verdadeira decomposição, de dessocialização que os vulnerabiliza como seres humanos.

As nossas sociedades desiguais, marcadamente injustas e excludentes, não só não conseguiram cumprir uma das promessas da modernidade que apontava para a gestão controlada das desigualdades através de políticas redistributivas e do pleno emprego, como veem agora manifestar, por novos processos econômicos, políticos e 
Gestão democrática e escola justa...

culturais, novos sistemas de desigualdades, seja no campo da educação, no da economia, no da cultura ou no da política.

Hoje, o raciocínio assenta-se não tanto em termos de igualdade, mas, antes em parâmetros de custo e eficácia, de maximização da eficiência mercantil, independentemente dos efeitos de exploração, competição e desigualdade que geram, acolhendo, pacificamente a ideia, por exemplo, de que é exigência de progresso a separação entre o econômico e o social, devendo pugnar se, simultaneamente pela integração econômica e pela desintegração social.

Ao mesmo tempo, os atuais movimentos de globalização levam-nos a colocar na ordem do dia a questão da justiça, uma vez que também aqui assistimos ao fato de a argumentação sobre a justiça está a alterar-se, salientando a pluralidade de sentidos consoante as várias definições, perspectivas e teorias sociais de que partimos, ao mesmo tempo que se exige um outro paradigma, o da "justiça democrática pós Westfaliana". (Fraser, 2007, p.37).

Este novo paradigma impõe a todos os sectores e, mormente à educação, novas exigências, designadamente em termos de aprofundamento das suas raízes democráticas e participativas, pugnando por uma maior simetria estrutural de poder, nos diferentes níveis de relações sociais (relações de trabalho, organizações, interações, tomada de decisões...). Impõe também a consideração das várias facetas da justiça, entendendo a não apenas como uma questão redistributiva, mas também de reconhecimento e de participa- ção a vários níveis e tendo presente a especificidade dos contextos em que se concretiza (Estevão, 2009).

Obviamente que este enquadramento não pode deixar de apontar para a centralidade das tensões e conflitos que estas diferentes dimensões implicam entre si, uma vez que, tal como defende Young (1990), nem todas as questões de justiça são redutíveis à distribuição, como é o caso, por exemplo, das questões resultantes da (injustiça da) normalização que eleva a experiência e as capacidades de alguns segmentos sociais em padrões face aos quais alguns comportamentos podem ser medidos e considerados desviantes.

Para Young (1990) a justiça social exige o desmantelamento das estruturas de opressão e dominação, embora estas duas faces não digam apenas respeito apenas ao modo como os recursos são distribuídos. Acrescenta, ainda, que a opressão apresenta cinco faces (a exploração, marginalização, ausência de poder, imperialismo cultural e violência, (Young, 1990) que não são redutíveis a uma única fonte comum, tal como não são solucionadas pela distribuição de recursos de modo igualitário).

Em suma, independentemente de alguns autores acentuem a justiça como distributiva ou econômica, que inclui, segundo Fraser (1997), a ausência de exploração, marginalização e privação material (embora a justiça distributiva possa incluir também aspectos acerca da distribuição de recursos sociais e culturais), ou de outros pretenderem sublinhar a justiça, sobretudo como justiça de reconhecimento (referida à ausência de dominação cultural, não reconhecimento e desrespeito, nas palavras de Fraser, 1997) ou como ausência da opressão e da dominação segundo Young 1990). Não deixa de ser 
verdade que outros apontam para a justiça participativa ou de associação, que tem a ver com os padrões de associação entre indivíduos ou grupos impedindo-os de participar integralmente nas decisões que afetam as condições em que eles vivem e atuam (Power \& Gewirtz, 2001).

\section{A ARTICULAÇÃO ENTRE JUSTIÇA E GESTÃO DEMOCRÁTICA NA ESCOLA}

É consensual que a escola pouco se tem modificado desde a modernidade, reproduzindo as mesmas desigualdades, embora vá produzindo e multiplicando novas desigualda- des também, conectadas com a relevância que determinados mundos e suas racionalida- des assumem no interior da escola.

Temos vindo a defender, a este propósito que, tal como a vida social é organizada segundo vários referenciais ou princípios reguladores, também a escola se constitui num lugar de vários mundos ou racionalidades, fato este que justifica várias definições da sua realidade organizacional.

A escola é, com efeito, uma organização complexa, uma rede de relações sociais materiais que organizam a experiência cotidiana e pessoal do aluno, uma organização, enfim, que apresenta várias faces e na sua acústica soam várias vozes e várias justiças. Aliás, é frequente usarmos na escola, diferentes léxicos e registros, movendo-nos entre a velha linguagem do serviço público (linguagem da igualdade de oportunidades) com as novas linguagens da gestão escolar e a linguagem do mercado (relações públicas, marketing, recrutamento); a linguagem da gestão financeira (orçamento); a linguagem da gestão organizacional (cultura organizacional, recursos humanos, qualidade, testes...). Tudo isto numa sobreposição clara de diferentes registros cognitivos obtidos por trocas comunicativas no interior da escola.

$\mathrm{Na}$ verdade, se existe uma multiplicidade e polimorfia dos princípios regulatórios na educação e na escola, torna-se logicamente defensável a afirmação de uma "dialetologia da justiça e dos direitos" na "ordem escolar", embora esta nem sempre seja muito visível devido à hegemonia e dominação da justiça oficial, ancorada, como sublinha Dubet (2004, p.6), na figura cardinal da "igualdade meritocrática de oportunidades", típica das sociedades democráticas que consideram todos os indivíduos livres e iguais em princípio, embora admitindo a sua distribuição em posições sociais desiguais. Ou seja, a relação entre os sistemas educativos e as doutrinas da igualdade de oportunidades e do mérito, sob a capa da justiça legitimam nas sociedades democráticas liberais a própria hierarquia social.

Neste sentido, o contributo da noção de "justiça complexa" (ou dos vários princípios de justiça) permitir-nos-á, desde logo, questionar a pertinência do conceito unívoco de justiça escolar, que, sob a forma de equidade formal e universal (e que tende a definir-se como o critério de cada um receber de acordo com a sua contribuição), reproduz de fato, embora de forma velada, uma pluralidade de formas de injustiça. Por outro lado, a escola é compreendida como uma organização plural, como uma arena de plurirracionalidades, 
de coordenação, de princípios argumentativos, de lógicas compósitas de justificação, ou de concepções plurais de justiça, obrigando por isso os atores educativos a coordenarem as suas ações, resolvendo os seus conflitos e dissensos locais, aprendendo, enfim, a passar de um sistema de referência ou de justificação para outro, a negociar interpretações diferentes da realidade escolar para que a escola, apesar de tudo, funcione com normalidade ou, pelo menos, dentro de regras mínimas de convivência e de uma coerência aceitável (Dubet, 2002).

Isto reforça a ideia de que os sujeitos escolares estejam, por um lado, despertos para um trabalho incessante e contínuo de justificação e de construção permanente deles mesmos no sentido de se tornarem verdadeiramente sujeitos, e, por outro, que estejam preparados para a negociação sobre a definição legítima da situação, tendo em vista a construção política de acordos ou de compromissos, assim como para a compreensão dos mecanismos de produção de "novas legitimidades educativas". Assim sendo, a ação organizacional escolar se explica não apenas pela socialização, mas também, pela economia das "razões práticas" ou das "boas razões" que reenviam, entre outros aspectos, as lógicas de comunicação contextualizadas (Dubet, 2002, p. 69).

Partindo desse enquadramento, torna-se particularmente interessante analisar como a própria experiência escolar dos alunos é argumentada em vários registros de justiça (por apelos ao mérito, à igualdade, à participação e ao respeito, à discriminação positiva, ao mínimo essencial educativo, às oportunidades de saídas profissionais, por exemplo), face à atuação dos professores, às interações que são privilegiadas, às práticas de avaliação adotadas, aos procedimentos disciplinares, às implicações da pedagogia que se perfilham. Contudo, temos clareza de que os conceitos de justiça e de práticas justas conceitos mediados por outras variáveis, nomeadamente a que tem a ver com a desigual distribuição de capital político, social e econômico dos alunos, com a especificidade dos contextos em análise, para além dos níveis que privilegiamos para realizar a investigação (ver Gewirtz, 2006).

Dubet (2010) afirma ter feito uso dos argumentos rawlsianos para pensar a justiça na escola hoje. Segundo o autor, devido à massificação escolar, a justiça na escola é vivenciada como tragédia: os princípios que a regem expressam intensos conflitos sociais, uma vez que a chamada "questão social" está dentro dos muros institucionais. Para ele, há vários princípios de justiça, muitas vezes contraditórios entre si, que legitimam a ação e interesses na escola. Para fazer frente à relação entre desigualdade social e desigualdade escolar, seria necessário considerar a impossibilidade de existência de uma escola totalmente justa. O autor afirma que, nos últimos 40 anos, a Sociologia da Educação tem se debruçado sobre o objetivo de obter a pura igualdade de oportunidades: meios pelos quais a escola poderia anular a reprodução da desigualdade social na produção da desigualdade escolar. Entretanto, nenhum país poderia, segundo ele, se gabar de ter conseguido superar o im- pacto da primeira sobre a segunda.

Ribeiro (2014) afirma que, para Dubet (2003), a explicação desse fato está na relação da escola com a justiça meritocrática, a qual transcende a própria instituição e 
encontra um sentido nos fundamentos das sociedades democráticas. Essas sociedades têm por característica a seguinte contradição: por um lado, têm como representações essenciais a igualdade fundamental (expressa na Declaração dos Direitos do Homem e do Cidadão) e a liberdade (expressa pela capacidade de agir, julgar e decidir por si), criando a represen- tação da liberdade de poder transcender circunstâncias de origem (nascimento, por exemplo); mas, por outro lado, são também estruturadas por hierarquias sociais, sendo que as posições vantajosas da vida social e política são raras.

Neste sentido, o contributo da noção de "justiça complexa" (ou dos vários princípios de justiça) permitir-nos-á, desde logo, questionar a pertinência do conceito unívoco de justiça escolar, que, sob a forma de equidade formal e universal (e que tende a definir-se como o critério de cada um receber de acordo com a sua contribuição), reproduz de fato, embora de forma velada, uma pluralidade de formas de injustiça. Por outro lado, a escola é compreendida como uma organização plural, como uma arena de plurirracionalidades, de coordenação, de princípios argumentativos, de lógicas compósitas de justificação, ou de concepções plurais de justiça, obrigando por isso os atores educativos a coordenarem as suas ações, resolvendo os seus conflitos e dissensos locais, aprendendo, enfim, a passar de um sistema de referência ou de justificação para outro, a negociar interpretações diferentes da realidade escolar para que a escola, apesar de tudo, funcione com normalidade ou, pelo menos, dentro de regras mínimas de convivência e de uma coerência aceitável (DUBET, 2002).

Isto reforça a ideia de que os sujeitos escolares estejam, por um lado, despertos para um trabalho incessante e contínuo de justificação e de construção permanente deles mesmos no sentido de se tornarem verdadeiramente sujeitos, e, por outro, que estejam preparados para a negociação sobre a definição legítima da situação, tendo em vista a construção política de acordos ou de compromissos, assim como para a compreensão dos mecanismos de produção de "novas legitimidades educativas". Assim sendo, a ação organizacional escolar se explica não apenas pela socialização, mas também, pela economia das "razões práticas" ou das "boas razões" que reenviam, entre outros aspectos, as lógicas de comunicação contextualizadas (DUBET, 2002, p. 69).

Continua Ribeiro (2014), indicando que Dubet (2009) exemplifica a referida contradição: o acesso às raras posições vantajosas, nessas sociedades, independe de transmissão por herança ou por fatores relativos às circunstâncias fixas (ser ou não de família nobre, por exemplo). Não havendo posições fixas por nascimento, os indivíduos precisam competir, recorrendo ao seu próprio esforço, para alcançar posições vantajosas. Diante dessa situação, para Dubet (2009), a escola passou a cumprir a função de organizar tal competição. E o mérito cumpre aí um papel articulador entre a igualdade fundamental dos indivíduos e a hierarquia das posições. Essa é, para o autor, a razão pela qual a justiça meritocrática tornou-se o princípio fundamental central da justiça escolar.

Carlos Estevão (2016) destaca que uma escola justa se faz também no seu cotidiano, através de ações e de procedimentos que indiquem o quanto todos os que circundam o universo escolar estão se esforçando para dar aos estudantes a certeza de 
que todos são iguais e assim serão tratados em todas as dimensões da vida escolar. Isso, porém, não pode levar à desconsideração das dificuldades de aprendizado e de sociabilidade que, por muitas razões, afetam mais a uns do que a outros. Assim, elementos universais e diferencialistas devem ser contemplados quando se fala de justiça escolar e de escolajusta.

\footnotetext{
Uma escola justa e de qualidade deve mobilizar a justiça escolar como igualdade de tratamento, quer no acesso, quer no sucesso, quer na possibilidade de permanecer no sistema [...], mas também a justiça diferencialista, dando mais aos que mais necessitam, designadamente aos que revelem dificuldades ou necessidades educativas especiais. Estes terão eventualmente de usufruir de políticas compen- satórias, no sentido de os tornar mais capazes de realizar o que de facto valorizam [...]. (Estevão, 2016, pp. 53-54).
}

Independentemente dessa percepção, a priori o desejo de justiça escolar parece ser indiscutível, como diria Dubet (2004). Porém, tal ideia não facilita a tarefa de definir uma escola justa, dado que existem diferentes maneiras de defini-la, nem sempre compatíveis entre si, como já dissemos. Por exemplo, os estudantes com problemas de aprendizagem/ comportamento podem estar em desvantagem numa das duas dimensões (redistribuição e reconhecimento) e a escola investir no sentido de ultrapassá-la, ou então verificar-se a situação de os estudantes serem injustiçados no duplo registro da distribuição e do reconhecimento, ao ser-Ihes negado o acesso aos recursos educacionais e ao mesmo tempo serem culturalmente marginalizados ao serem tratados como crianças - problema. Noutros termos, a justiça meritocrática, apanágio das sociedades liberais democráticas, pode virar-se contra a justiça cívica ou cidadã, privilegiando outros valores mais de pendor industrial ou gerencialista.

A democracia como mais do que uma forma de governo. É também um modo de vida, pressupondo valores que devem ser adotados e vivenciados pela totalidade da população, em suas experiências pessoais e sociais.

A escola, como organização social, também pretende ser um espaço democrático, de modo que os educadores profissionais, os alunos, os pais, os ativistas comunitários e outros cidadãos do contexto social imediato tenham o direito de estar bem informados e de ter uma participação crítica na criação e na execução das políticas e dos programas escolares. Vê-se, aqui, dois elementos fundamentais para a concretude da democratização da escola: a participação de todos os componentes da comunidade escolar nos processos decisórios e a existência de um amplo processo de informação em que todos tenham conhecimento do que acontece no interior da instituição e suas relações externas.

Para garantir que uma escola seja verdadeiramente democrática, é preciso considerar ainda dois outros elementos:

a) a criação de estruturas e processos democráticos pelos quais a vida escolar realiza-se, representada pela participação geral nas questões administrativas e políticas, pelo planejamento cooperativo na escola e na sala de aula, pelo atendimento a preocupações, expectativas e interesses coletivos, e pela posição firme contra o racismo, a injustiça, o poder centralizado, a pobreza e a quaisquer formas de exclusão e 
desigualdade presentes na escola e na sociedade;

b) o desenvolvimento de um currículo que ofereça experiências democráticas aos estudantes, cujas características são expressas pela ênfase na ampliação das informações; garantia aos que têm opinião diferente, do direito de se fazerem ouvir; construção social do conhecimento; formação de leitores críticos da realidade; inclusão de um processo criativo de ampliação dos valores democráticos; inclusão de experiências de aprendizado organizado em torno da problematização e do questionamento.

No Brasil, a questão da democratização da escola pública tem sido analisada sob três aspectos, de acordo com a percepção dos órgãos oficiais ou na perspectiva dos educadores, especialmente daqueles que fazem uma leitura mais crítica do processo educacional: democratização enquanto ampliação do acesso à instituição educacional; democratização dos processos pedagógicos e democratização dos processos administrativos. Os órgãos oficiais entendem a democratização do ensino como a facilidade do acesso à escola pelas camadas mais pobres da população. Para tal desenvolvem programas que têm como principal objetivo o aumento do número de escolas e de salas de aula, garantindo o seu discurso de universalização do ensino. No entanto, na prática, não atentam adequadamente para as condições mínimas necessárias para a efetivação desse processo "democrático", oferecendo insuficientes salários aos professores e condições de trabalho desfavoráveis ao ensino e à aprendizagem.

Uma segunda forma de encarar a democratização da escola é considerá-la como o desenvolvimento de processos pedagógicos significativos, pela adoção de um currículo concreto e vivo que garantam a permanência do estudante no sistema escolar, eliminando e impedindo o processo de exclusão representado pela evasão e repetência.

Outra forma é a de compreender que a democratização se realiza pelas mudanças nos processos administrativos desenvolvidos nos sistemas educacionais e no interior das escolas, por meio da participação de pais, alunos, professores e da sociedade civil em geral nas decisões tomadas em assembleias, de eleições para os cargos diretivos e da eliminação das vias burocráticas de gestão.

A análise de cada uma dessas concepções permite a conclusão de que o processo de democratização da escola só será completo quando houver a combinação orgânica dos três aspectos. Portanto, não basta criar escolas. É necessário, por um lado, criar estruturas e processos democráticos, por meio dos quais a vida escolar se realize, e, por outro lado a construção de um currículo crítico e criativo, cuja organização estrutural seja de tal modo flexível e aberta que ofereça experiências democráticas ao estudante, tudo isso alicerçado em procedimentos dos sistemas educacionais que possibilitem à escola o exercício da autonomia, a descentralização das decisões e a adoção da gestão colegiada.

Assim, gestão democrática rompe concepções, paradigmas e posturas para realizar a transformação das relações intersubjetivas, compreendendo, antes e acima das rotinas administrativas, a identificação de necessidades; a negociação de propósitos; a definição clara de objetivos e estratégias de ação; as linhas de compromissos; a coordenação e o acompanhamento de decisões pactuadas, mediação de conflitos, com ações voltadas para 
a transformação social, concretizando-se através dos seguintes princípios, apontados também por Bordignon e Gracindo, (2000): voltada para a inclusão social; fundada no modelo cognitivo/afetivo; com clareza de propósitos, subordinados aos interesses dos cidadãos a que serve; com processos decisórios participativos e tão dinâmicos quanto a realidade, geradores de compromissos e responsabilidades; com processos auto avaliadores geradores da crítica institucional e fiadores da construção coletiva.

A escola, na qualidade de organização social de formação, pretende ser espaço onde todos aprendem sobre justiça e a democracia, vivendo seus valores num exercício permanente, construídas por pequenas conquistas diárias, na vida da coletividade, para alcançar grandes conquistas. A participação da comunidade nas decisões mais simples da escola é tão importante e justa quanto sua participação em decisões mais complexas que envolvem as políticas educacionais ainda definidas apenas pelos órgãos federais, estaduais e municipais.

\section{CONSIDERAÇÕES QUASE FINAIS}

Apresentados os diversos conceitos, verificamos que a justiça e a democracia estão correlacionadas às questões igualdade e liberdade. Esses conceitos, embora amplos, norteiam as ações humanas a partir de valores socialmente desenvolvidos que foram amplamente debatidos e aceitos racionalmente pela sociedade. Porém, na atualidade da sociedade brasileira, percebemos que a esfera da justiça vem sendo ferida com a permanência e a ampliação das desigualdades.

As concepções que se tem acerca de justiça são tão diversas quanto os princípios utilizados para defini-la. Assim, por exemplo, há autores que defendem a perspectiva universalista, que afirma que ser justo é tratar da mesma forma os seres que são iguais em certo ponto de vista, que possuem uma mesma característica, a única que se deve levar em conta na administração da justiça, afirmando que uma sociedade pode ser considerada justa quando todos os cidadãos adotam a mesma concepção de justiça, atuando conforme os princípios aceitos por todos como justos. Entretanto, alguns autores, contrariando as posições universalistas, defendem a justiça sob as perspectivas pluralista e radical que compreendem a justiça de forma mais ampla, societária e inclusiva.

Parece não haver dúvidas também que uma escola justa preservaria melhor a dignidade e a autoestima dos que não fossem tão bem-sucedidos, mas tal supõe outros tipos de ação, desde logo, a afirmação do papel educativo e cultural da escola não apenas ao nível da instrução, mas também nas atividades culturas e desportivas, na organização da própria vida escolar, no atendimento dos alunos fora da classe. No caso dos professores, a dignificação de seu trabalho, a garantia do respeito por suas idiossincrasias e a valorização de seus saberes e fazeres.

Consideramos que, além da contribuição teórico-metodológica que os resultados deste estudo trazem para o campo educacional, também expressam relevância acadêmico-científica, na medida em que irão possibilitar melhor compreensão de 
concepções que fundamentam as propostas de organização escolar mais justa para a educação e o ensino brasileiros.

Relativamente à gestão democrática na escola, apesar do aumento do gerencialismo trazido pela NGP e pela ideia da gestão compartilhada que consolida as práticas centralizadoras, é possível ser concretizada e, assim, discutida, defendida e mantê-la.

De nossa parte continuamos com o permanente estudo a respeito das concepções de educação e justiça e vimos encontrando articulação orgânica da justiça com a participação democrática na gestão escolar o que mantém nossa convicção de que esta é a via mais legítima para consolidação da melhoria da qualidade do ensino e da consciência crítica da realidade social para a construção de uma escola verdadeiramente pública, do bem comum. Justa. 


\section{REFERÊNCIAS}

BOLTANSKI . Luc \& THÉVENOT, Laurent. De la justification economies de la grandeur. Paris, Galli- mard, 1991.

BORDIGNON, G. e GRACINDO, R. V. Gestão da educação: o município e a escola. In: FERREIRA, N. S. C. e AGUIAR, M. A. da S. (orgs.). Gestão da educação: impasses, perspectivas e compromissos. S. Paulo: Cortez, 2000.

DUBET, F. As Desigualdades Multiplicadas. ljuí/RS: Ed. Unijuí, 2003. DUBET, F. Le déclin de l'insti tuti on. Paris: Seuil, 2002.

DUBET, F. Les dilemmes de la justice. In: DEROUET, Jean-Louis; DEROUET-BESSON, Marie-

-Claude (Éd.).Repenser la justice dans le domaine de l'éducation et de la formation. Lyon: Peter Lang, 2009. p. 29-46.

DUBET, F. Les Places et les chances. Repenser la justice sociale. Paris: La République de Idées/ Seuil, 2010.

DUBET, François. O que é uma escola justa? Cad. Pesquisa, São Paulo, v. 34, n. 123, p. 539-555. dez. 2004. Disponível em: htt p://www.scielo.br/scielo.php?script=sci_artt ext\&pid=S0100--15742004000300002\&lng=pt\&nrm=iso. Acesso em 22 jun. 2010.

ESTEVÃO, Carlos V. Justiça social e modelos de educação: para uma escola justa e de qualidade. Revista Diálogo Educacional, v. 16, n. 47, pp. 37-58, 2016. Disponível em: http://bit.ly/2OLRhm9. Acesso em: 6 set. 2018.

ESTEVÃO, Carlos Alberto Vilar. Educação, justiça e democracia: um estudo sobre as geografias da justiça em educação. São Paulo: Cortez, 2004.

ESTEVÃO, Carlos Vilar. Educação, globalizações e cosmopolitismos: novos direitos, novas desi- gualdades. Rev. Port. de Educação, vol.22, №. 2, p.35-52. 2009. ISSN 08719187.

ESTEVÃO, Carlos Vilar. Novas desigualdades, novos direitos e cosmopoliti smos: para uma política educacional e uma administração da educação cosmopolíti cas. Caderno de Pesquisa: Pensamento Educacional, volume 4, no. 7, jan-jun, 115- 137. 2009.

FRASER, N. Justice Interruptus: Critical Reflections on the "Postsocialist" Condition. Cambridge: Routledge, 1997.

FRASER, N. Reframing justice in a globalizing world. D. Held \& A. Kaya (Eds.), Global Inequality. Cambridge: Polity Press, 2007, p. 252-272.

GEWIRTZ, S. Towards a contextualized analysis of social justice in education. Educational Philosophy and Theory 1, (1), 2006. p.69-81.

HORA, Dinair Leal da e LÉLIS, Luziane Said Cometti. O significado de escola justa para estudantes da escola básica amazônida e a organização dos processos educativos. Humanidades \& Inovação. v.7, n.15 - 2020. 
RAWLS, John. Uma teoria da justiça. 3 ed. São Paulo: Martins Fontes, 2008.

RIBEIRO, Vanda Mendes. Que princípio de justiça para a educação básica? Cadernos de Pesqui- sa. v.44 n.154 p.1094-1109 out./dez. 20141097.

SILVA, Sidney Reginaldo da. Razoabilidade, pluralismo e educação segundo John Rawls. Dis- sertação de Mestrado, PUC-Rio, 2004. Disponível em: http://www.maxwell.lambda.ele.puc-rio. br/8709/8709.

TAVARES, Felipe Cavaliere. Michael Walzer e as Esferas da Justiça. Trabalho publicado nos Anais do XVIII Congresso Nacional do CONPEDI, São Paulo -, novembro de 2009.

WALZER, Michael. Esferas da justiça: uma defesa do pluralismo e da igualdade. São Paulo: Martins Fontes, 2003.

YOUNG, Iris M. Justice and the politics of difference. Princeton: Princeton University Press, 1990. 